\title{
Policy Implications of Digital Television
}

\author{
Bartolomeo Sapio \\ Fondazione Ugo Bordoni, Viale del Policlinico 147, 00161 Roma, Italy \\ bsapio@fub.it
}

\begin{abstract}
This section is an exploratory study about factors affecting the usage of T-government services for payments through Digital Terrestrial Television (DTT) and how policy measures can influence adoption. The widely known predicting model of ICT user acceptance UTAUT (Unified Theory of acceptance and Use of Technology) is applied to recognize those factors affecting usage, exploiting a dataset coming from an Italian T-government project. Tgovernment stands for a wide set of services addressed to citizens (e.g. about health, education, tourism, payment of bills), delivered by a Public Administration or a private provider, and accessible through Digital Television. One of the opportunities given by T-government is to promote the use of ICT-based public services by large groups of people (e.g., the elderly), who haven't got any Internet access or the required skills to use it.
\end{abstract}

Keywords: Digital Terrestrial Television, policy measures, T-government, Unified Theory of acceptance, Use of Technology.

\section{European Policies toward Digital Terrestrial Television}

The introduction of Digital Terrestrial Television (DTT) is derived from the process of implementing the recommendations of the European Union: while they preserve competition between terrestrial, satellite and cable platforms within the EU market, the recommendations provide forms of public intervention such as: funding for pilot and research projects, subsidies for the purchase of decoders for any platform in order to prevent the exclusion of low-income families from access to TV reception, subsidies to companies (to develop innovative digital services) and broadcasters (to compensate for the additional transmission costs due to the parallel broadcasting of analogue and digital signals, the so-called "simulcast phase"). In this context, the major European countries have adopted policies that have led to high rates of digitization in families. Support policies have aimed to provide continuity of service in each country, especially considering that most of the population (particularly the weakest layers) uses television as the main source of information.

Table 1 outlines various policies carried out in four major European TV markets: Italy, France, United Kingdom and Spain. 
Table 1. European policies for Digital Television (Source: Digital UK, Ofcom, Impulsa TDT, CSA, Agcom, DGTVi, Booz \& Company)

\begin{tabular}{|c|c|c|c|c|}
\hline & Italy & France & $\begin{array}{l}\text { United King- } \\
\text { dom }\end{array}$ & Spain \\
\hline $\begin{array}{l}\text { Subsidies to } \\
\text { users }\end{array}$ & $\begin{array}{l}\text { Regional } \\
\text { subsidies to } \\
\text { purchase } \\
\text { DTT } \\
\text { decoders in } \\
\text { switch-off } \\
\text { regions }\end{array}$ & $\begin{array}{l}100 \text { million } \\
\text { Euros (in } 3 \\
\text { years) for } \\
\text { families } \\
\text { including } \\
\text { elderly or } \\
\text { disabled people } \\
85 \text { million } \\
\text { Euros (in } 3 \\
\text { years) for low } \\
\text { income } \\
\text { families }\end{array}$ & $\begin{array}{l}603 \text { million } \\
\text { pounds for the } \\
\text { Digital Switch- } \\
\text { over Help } \\
\text { Scheme (subsi- } \\
\text { dies to target } \\
\text { families) }\end{array}$ & $\begin{array}{l}110 \text { million } \\
\text { Euros (in } 2008 \\
\text { and } 2009 \text { ) for } \\
\text { regional } \\
\text { communication } \\
\text { and support to } \\
\text { vulnerable groups }\end{array}$ \\
\hline $\begin{array}{l}\text { Subsidies to } \\
\text { broadcasters }\end{array}$ & $\begin{array}{l}33 \text { million } \\
\text { Euros (2007) } \\
\text { to RAI for } \\
\text { DTT }\end{array}$ & $\begin{array}{l}\text { Reserved } \\
\text { channels for } \\
\text { traditional free- } \\
\text { to-air } \\
\text { analogical } \\
\text { broadcasters, in } \\
\text { exchange for } \\
\text { the transition of } \\
\text { broadcasting } \\
\text { networks to } \\
\text { digital }\end{array}$ & $\begin{array}{l}\text { Renewal of } \\
\text { licenses in } \\
\text { exchange for } \\
\text { the transition } \\
\text { of } \\
\text { broadcasting } \\
\text { networks to } \\
\text { digital }\end{array}$ & $\begin{array}{l}\text { Contributions to } \\
\text { increase TDT } \\
\text { coverage ( } 8.7 \\
\text { million Euros in } \\
2008)\end{array}$ \\
\hline $\begin{array}{l}\text { Industrial } \\
\text { choices }\end{array}$ & $\begin{array}{l}\text { Obligation of } \\
\text { DTT tuner } \\
\text { in iDTV } \\
\text { DGTVi } \\
\text { quality } \\
\text { certification }\end{array}$ & $\begin{array}{l}\text { Obligation of } \\
\text { DTT tuner in } \\
\text { iDTV } \\
\text { Push towards } \\
\text { HD } \\
\text { TNT quality } \\
\text { certification }\end{array}$ & $\begin{array}{l}\text { Freeview } \\
\text { quality } \\
\text { certification }\end{array}$ & $\begin{array}{l}\text { Push towards } \\
\text { MHP decoders }\end{array}$ \\
\hline
\end{tabular}

\section{T-Government Pilot Projects}

T-government stands for a wide set of services addressed to citizens (e.g., about health, education, tourism, payment of bills), delivered by a Public Administration or a private provider, and accessible by Digital Television. One of the opportunities given by T-government is to promote the use of ICT-based public services by large groups of people (e.g., the elderly), who haven't got any Internet access or the required skills to use it. For those people the past experience with TV and remote control may be a key qualification to become effective users of the above mentioned services. In this way the inclusion in the benefits of information society of culturally disadvantaged people can be encouraged (e-inclusion). 
On these topics field investigations have been developed in Italy in the framework of the T-government projects promoted by Fondazione Ugo Bordoni (FUB). One of the objectives of the six T-government projects co-funded by FUB was to experiment high interactivity T-government services, realized by DTT involving real users.

The main aim of this study was to investigate the use behavior during the diffusion of DTT services. A multidisciplinary approach, in particular the framework provided by the human factors discipline, was adopted in order to focus the attention on the variables affecting both usage-usability and socio-economic aspects. In such a perspective a predicting model of ICT user acceptance, i.e. the UTAUT model [6] [7], was applied to recognize those factors directly affecting the usage. As a second step, a micro simulation model was implemented to investigate the diffusion patterns of both Digital TV and T-government services. The adopted innovative methodology progressed through the following main steps by:

1. Collecting general information about governmental policies, current state of DTT penetration in Italy as well as other T-government field investigations;

2. Structuring the data gathered in the Italian pilot studies to feed the micro simulation model;

3. Identifying the most relevant factors affecting services usage;

4. Building up the micro simulation model; and

5. Generating scenarios about citizens' adoption and use behavior of DTT services.

Given the existing general policy constraints, different strategic scenarios of citizens' adoption and use of DTV services offered by a public provider were envisaged to be dependant upon the governmental decisions, i.e. tax reduction, public communication campaign, and analogue system switch-off date.

The experimented services belong to different application areas: demographics, utilities and fines, education, T-health, T-learning, employment, T-commerce, T-banking. In order to investigate usage, usability and socio-economical aspects of T-government services, an explorative field investigation was developed in each of the six projects.

The field investigations were realised using a common framework referring to human factors discipline [4]. The following main usability aspects related to interactive services were identified: perceived usefulness, perceived ease of use and attractiveness, training and user support (human support, user manual, support provided by DTT, call centre), user perception of technical disturbances and troubles (due to television signal, set top box, return channel), security and privacy perception (confidentiality of personal data, security of payments), impact of the equipment in the house, users' satisfaction about the service including the comparison of different channels to perform the same task (e.g., DTT versus Internet, DTT versus traditional office desk).

The adopted indicators for service utilisation level are [1]: frequency of use, time duration of the session, and kind of use (shallow or intensive). Socio-economical aspects include user profile (including income and social network information), TV and Internet usage (including other entertainment technologies), and scenarios 
(including interest levels, willingness to pay for equipment and services, decision factors).

Services developed in three of the six projects are still "on air" after the end of the project. These services have the common feature of being provided in the context of a public administration (municipality, regional administration, public schools).

In the following sections three pilot studies are introduced, analyzing the effect of policy measures on the diffusion. Methodological issues are discussed in detail in the referenced papers.

\subsection{Pilot Study "Parma Municipality Services"}

The project "Parma Municipality Services" [5] has developed both informative and interactive services. The former provide information about: Parma Municipality organisation; services offered to the citizens by the Municipality; cultural initiatives in progress in the city.

The interactive services allow the user (after the authentication through the Electronic Identity Card):

- to pay fines using a credit card;

- to visualise the state of a demographic dossier (e.g., for changing place of abode);

- to visualise the state of a request for education services provided by the municipality (e.g., nursery school).

A sample of 200 people was selected from a group of 4.000 citizens of Parma $\mathrm{Mu}-$ nicipality. It was decided to choose the sample age ranging from 20 to 45 years, people in general skilled in the use of new information technology. The 200 citizens were randomly selected in this age range. Finally, 181 citizens (88 males and 93 females) took part in the experiment for the all planned period of two months and a half. Data were collected mainly using a paper-based questionnaire filled in by the users. The questionnaire was both delivered and collected by Municipality of Parma personnel.

\section{Scenarios}

Alternative reference scenarios are presented hereafter in Figure 1 and Figure 2. They are not intended to be predictive, but only to investigate the model mechanisms.

Scenario 1: Switch off in 2013, No subsidy, No communication. In the first year, all adopters do not use services. The year after, all of them use only information services. Then, throughout four years, the adopters are divided between those who use interactive and information services and those (the major part) who exploit only information services, and their total number remains constant and equal to the initial value. After the switch off, when all users become adopters, there is no increase of real users of services for one year. After that, a great rise of the users of information services can be observed and, a year later, a more limited increase of the users exploiting both information and interactive services occurs too, with a corresponding decrease of information service users. 


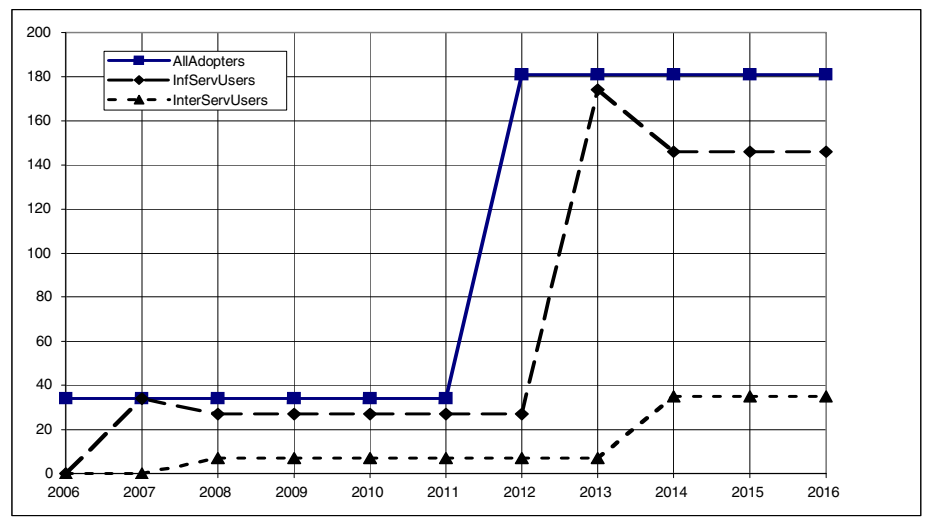

Fig. 1. Results from different policy scenarios in scenario 1

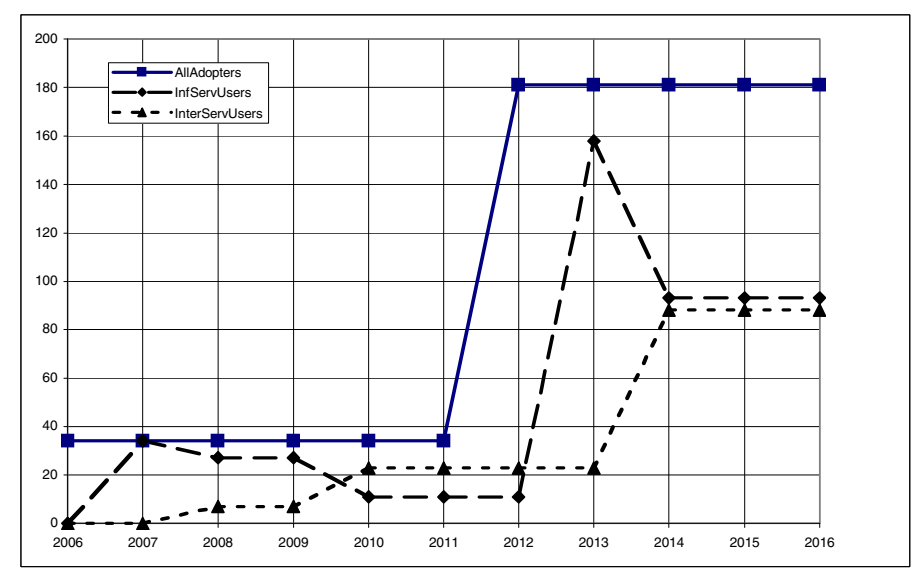

Fig. 2. Results from different policy scenarios in scenario 2

Scenario 2: Switch off in 2013, Communication (level 2) 2010-2014, No subsidy. The most important variation introduced by an intense communication lasting from 2010 to 2014 (in absence of subsidization) is in the sharing of users between information service users and users of both information and interactive services, thus, in the shaping of relevant lines. Two inversions of dominance can be observed before the two classes of users reach constant and very close final numbers of elements.

\subsection{Pilot Study "Employment Services"}

The project "Employment Services" [2] developed a DTV portal to provide support especially to young people - in finding a job. The DTV portal was organized in four sections:

1. Search for a job

2. Search for information useful to find an employment 
3. T-commerce. It was possible to buy books and to pay using a credit card

4. T-learning. Broadcast lessons were delivered

A panel of about 400 users was involved in the field study. The panel was distributed in the geographical areas of Pisa, Lucca and Livorno in Tuscany region. The users were selected with the criteria to be potentially interested in finding a job. As a consequence, they were belonging to the range of age in which is probable to search for an employment. The users were mainly recruited among the users participating in a previous study about DTV utilization, so that most part of them was equipped in advance with the set-top box.

\section{Scenarios}

Alternative reference scenarios are presented hereafter. In the scenario generation process, three different policies and combinations of them have been tested:

- Policy $\boldsymbol{E} \boldsymbol{E}$ : design of DTV applications with increased usability to reduce the user's effort expectancy

- Policy PE: communication campaign to increase the user's performance expectancy from DTV services

- Policy FC: user support (through call centers and similar) to create facilitating conditions.

Figure 3 shows the adopters' curve as generated by the micro simulation model. It is not influenced by the different policies and only depends on Bass model parameters $(p=0.014, q=0.726)$ [7].

The first DTT users in Italy came in 2004, the year of take-off. The adoption rate is slow during the first years and becomes progressively quicker when the switch-off date gets closer. As an intrinsic characteristic of the model, all users become adopters from 2013, when analog broadcast is no longer in operation. The dashed line represents the adoption as it would happen according to the "pure" Bass model, the full line includes also the effect of switch-off.

Scenario 1: No policies. The use behavior (mean number of monthly interactions) of T-government services without any governmental policies is shown in Figure 4. The use behavior has been obtained by the item of the questionnaire "frequency of use of the portal sections in the last month". The dashed lines respectively represent the standard deviation. In this scenario the growth is quite regular, slower during the first years and somehow quicker from 2009, without any singularities. Variations are not very significant and the mean number of monthly interactions remains relatively low during the entire time horizon.

Scenario 2: Combination of policies EE, PE and FC 2009-2020. Figure 5 shows a scenario where a combination of three different policies (EE, PE and FC) is implemented from the year 2009 to the end of the simulation period. This scenario conveys a significant increase of the monthly frequency of use during the implementation of the policies, reaching a nearly triple regime value. The standard deviation is quite significant in the transition period, suggesting that some users are reluctant to use T-government services while others are ready to exploit the new possibilities opened by digital television. 


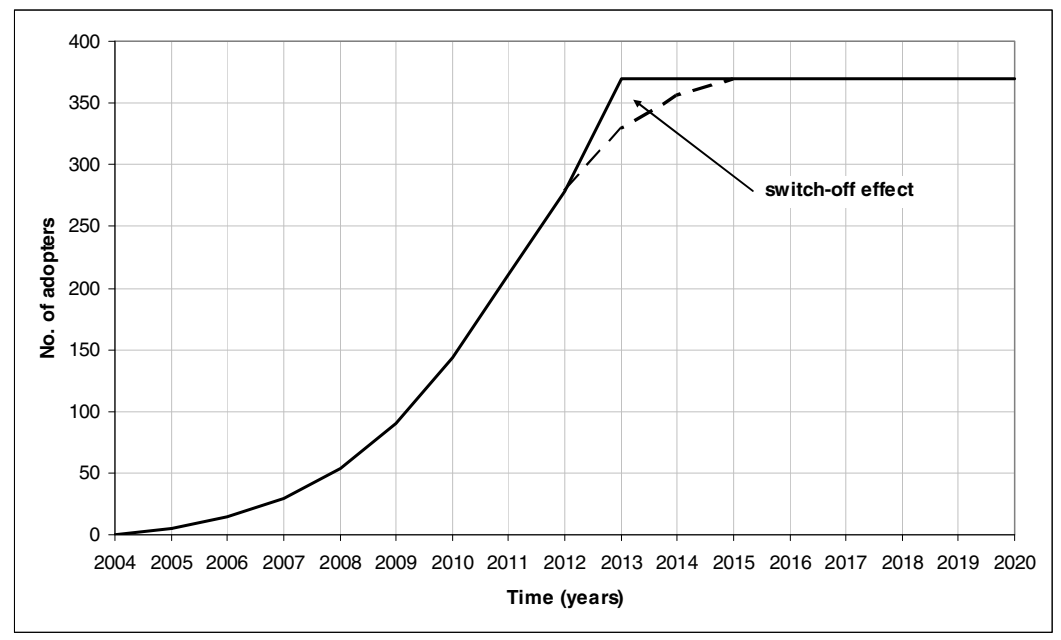

Fig. 3. Adopters' curve

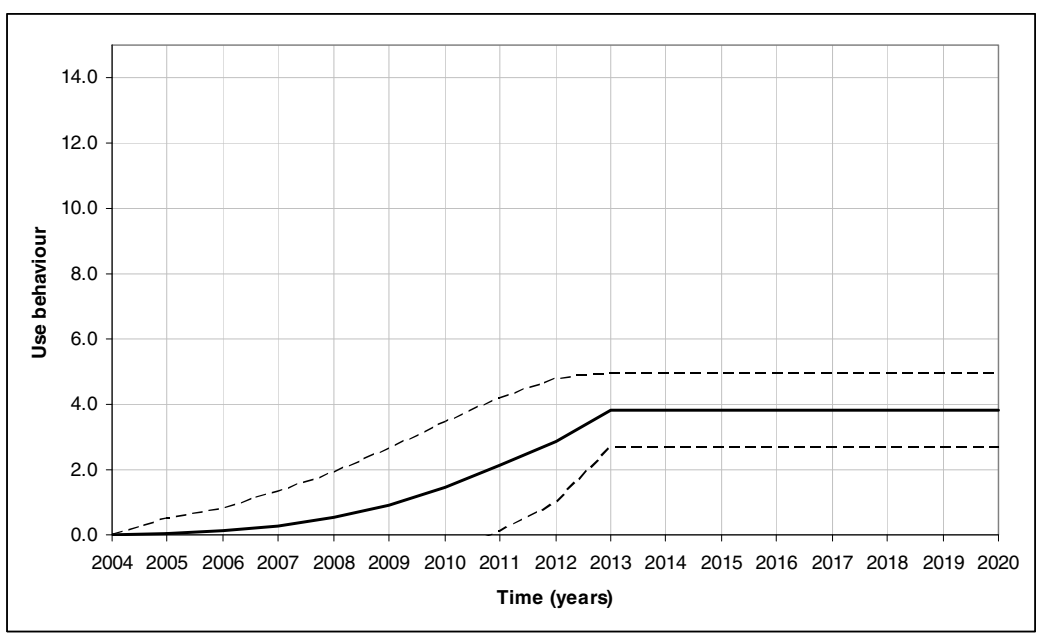

Fig. 4. Scenario 1 - No policies

\subsection{Pilot Project "T-Bollettino"}

T-Bollettino [3] is an interactive service providing the user with

- remote interactivity using the return channel

- user identification and authentication using a smart card

- on line payment functionality

The return channel is connected to the DTV service centre of the project, and the broadcasting system broadcasts the application. 
The service allows bills' payment through DTV for gas, phone, local taxes, fines, road taxes. The payment can be realized using a credit card, a prepaid card (Postepay) or by charging the account "Bancoposta Online".

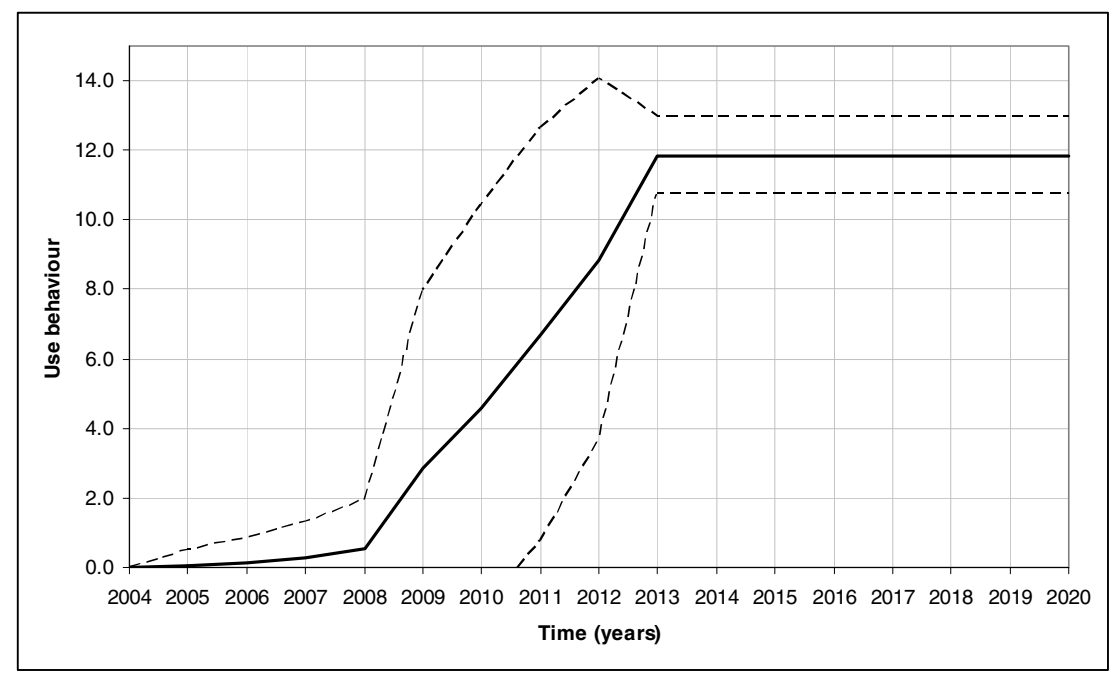

Fig. 5. Scenario 2 - Combination of policies EE, PE and FC

A panel of about 300 users was involved in the field study. The panel was uniformly distributed in the North, Centre (City of Roma) and South of Italy. The users were selected with the criteria to be representative of Italian families in terms of number of components of the family, age of head of the family, education of head of the family, job of head of the family. Only people usually paying bills at the post office and owners of a credit card, a prepaid card (Postepay) or the current account "Bancoposta" were included in the users' panel.

\section{Scenarios}

The impact of three different policies and combinations of them has been tested:

- Policy PE: communication campaign to increase the user's performance expectancy from DTV services

- Policy FC: user support (through call centers and similar) to create facilitating conditions.

- Policy PS: communication campaign or security interventions on applications to increase the users' perceived security

The simulation model allows to test the impact of two different intensity levels for each policy (level $1=$ moderate, level 2 = strong). Policies based on effort expectancy (e.g., design of DTV applications with increased usability) have not been considered, since the effort predictor had a non-significant impact. 


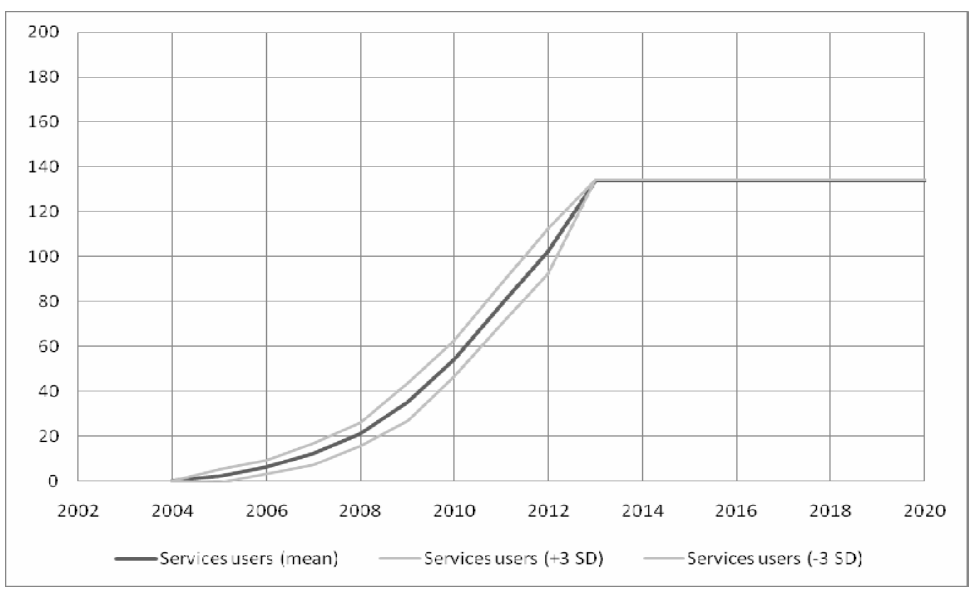

Fig. 6. Scenario 1 - No policies

Scenario 1: No policies. The use behavior (number of users of the service T-bollettino) without any governmental policies is shown in Figure 6. The use behavior has been obtained by the item of the questionnaire B21 "intention to use the T-bollettino service". The bold line represents the mean value, whereas the thin lines refer to minus and plus three times the standard deviation. In this scenario the growth is quite regular, slower during the first years and somehow quicker from 2009, without any singularities. The regime value is slightly below three quarters of the total number of DTV users and it is reached after the switch off in 2013.

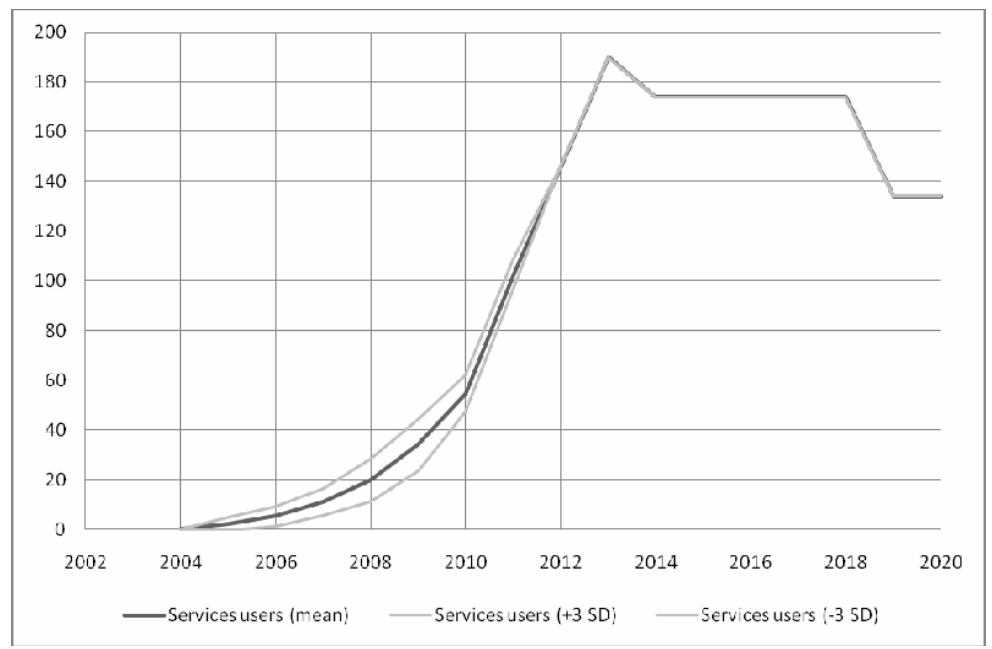

Fig. 7. Scenario 2 - Combination of policies PE (level 2) and FC (level 2) 
Scenario 2: Combination of policies PE 2012-2013 (level 2) and FC 2011-2018 (level 2) Figure 7 shows a scenario where a combination of two different policies (PE and FC) is implemented in a realistic situation, where a communication campaign is financed by the national government for a couple of years around the switch off date with a strong level of intensity and a constant support to users through call centers and similar is provided for many years. The number of users who try the T-bollettino service goes to its upper limit in conjunction with the simultaneous action of the switch off, the campaign and the support, falling back to the regime value in two steps toward the end of the implementation of the policies.

\section{Conclusions}

The main aim of the study was to investigate user adoption and use behavior during the diffusion of DTV interactive services for citizens. The main result was a micro simulation model producing different strategic scenarios on citizens' use of DTV services depending on policies about DTV interactive service design, the informative campaign and as well as the support given to the residential population. The following main indications can be extracted from the scenarios:

- The adoption of a user centered design approach produces a significant increase of the frequency of use of the services during the implementation of the policy, in comparison to the scenarios in which no specific policies are adopted.

- Similarly, the realization of an intense communication campaign to showcase DTT services benefits to citizens produces a significant increase of the frequency of use during the implementation of the policy.

- The realization of a policy based on the provision of a strong user support (e.g., through a call centre) seems to produce smaller effects on use behavior in comparison to other policies.

- A combination of different policies conveys a significant increase of the service frequency of use during the implementation of the policies themselves.

These indications about the diffusion of interactive services are related to the limited context of the Italian pilot study. However, final results and achievements confirm that the adopted methodology is adequate for the study applied to the residential population. They also encourage future developments in the utilization of the UTAUT model. In fact, at this stage of the study about the usage of T-government services, the UTAUT key moderators (i.e. age, gender, experience, voluntariness of use) were not included in the process. On this respect a further analysis has been planned to aim at finding whether it is possible to incorporate in the model, in addition to the UTAUT key moderators, also the variables "income" and "education", either as new moderators or as new determinants.

Acknowledgements. These investigations were developed in the framework of the project "Monitor DTT" (Monitoring user experience with DTT) carried out by Fondazione Ugo Bordoni for the Italian Ministry of Economic Development - Department 
of Communication. The author wishes to warmly thank team members Michele Cornacchia, Enrico Nicolo' and Filomena Papa (FUB), and Stefano Livi (Sapienza University of Rome).

Open Access. This article is distributed under the terms of the Creative Commons Attribution Noncommercial License which permits any noncommercial use, distribution, and reproduction in any medium, provided the original author(s) and source are credited.

\section{References}

1. Davis, F.: User acceptance of information technology: system characteristics, user perceptions and behavioral impacts. Int. J. Man-Machine Studies, AP 38, 475-487 (1993)

2. Papa, F., Nicolo', E., Cornacchia, M., Sapio, B., Livi, S., Turk, T.: Adoption and use of digital tv services for citizens. In: Proceedings of the COST 298 Conference "The Good, the Bad and the Challenging", Copenhagen, pp. 161-171 (2009)

3. Papa, F., Nicolo', E., Livi, S., Sapio, B., Cornacchia, M.: Factors Affecting the Usage of Payment Services through Digital Television in Italy. In: Proceedings of EuroITV 2010, Tampere, June 9-11 (2010)

4. Papa, F., Spedaletti, S.: Broadband cellular radio telecommunication technologies in distance learning: a human factors field study. Personal and Ubiquitous Computing 5, 231-242 (2001)

5. Sapio, B., Turk, T., Cornacchia, M., Papa, F., Nicolò, E., Livi, S.: Building scenarios of digital television adoption: a pilot study. Technology Analysis \& Strategic Management 22(1), 43-63 (2010)

6. Venkatesh, V., Davis, F.D.: A theoretical extension of the technology acceptance model: Four longitudinal field studies. Management Science 46(2), 186-204 (2000)

7. Venkatesh, V., Morris, M.G., Davis, G.B., Davis, F.D.: User Acceptance of Information Technology: Toward a Unified View. MIS Quarterly 27(3), 425-478 (2003) 